\title{
O TROPICALISMO E SEU PROJETO POLÍTICO IDEOLÓGICO: UM EXERCÍCIO DE LEITURA
}

\author{
Rafael Marino*
}

Este ensaio pretende expor algumas notas de pesquisa a respeito do tropicalismo. Sabe-se que tropicália já fora tema de diversos estudos nas ciências humanas e sociais, contudo aposta-se num outro ângulo para seu estudo: o seu projeto político e ideológico. Este projeto, segundo nossa hipótese, teria logrado consolidar um modo de pensar o Brasil que, grosso modo, baseava-se na transfiguração das especificidades sociais e culturais do Brasil em qualidades e respostas de nossa 'civilização' brasileira perante o mundo e seus problemas. Dando consecução ao nosso argumento, exporemos alguns lineamentos dos pensamentos de alguns personagens destacados da tropicália sobre o Brasil. Para tal, lançaremos mão de alguns escritos e depoimentos de seus partícipes.

Palavras-chave: Pensamento político e social brasileiro; estética e política; tropicalismo.

\section{INTRODUÇÃO}

Sabe-se que a tropicália já fora tema de diversos estudos nas ciências humanas e sociais, contudo aposta-se, neste ensaio, num outro ângulo para seu estudo: o seu projeto político e ideológico. Este projeto, segundo nossa hipótese, teria logrado consolidar um modo de pensar o Brasil que, grosso modo, baseava-se na transfiguração das especificidades sociais e culturais do Brasil em qualidades e respostas de nossa 'civilização' brasileira perante o mundo e seus problemas. Tal hipótese inspira-se em quatro influências distintas.

A primeira é a de Duarte (Cf. 2014) sobre o modernismo, no qual o autor encara, em linhas gerais, este movimento na chave de um projeto ideológico entre a revolução e o carnaval, como se uma coisa dependesse da outra, pois a exaltação do carnaval brasileiro teria propiciado tanto uma valorização da cultura popular, desprezada historicamente no país, quanto um modelo de devoração, sem exclusão ou cópia, de influências externas. Ajudando a forjar um ideário político e estético que iria contra o filisteísmo cultural da burguesia nacional; contrariedade revoltosa que será pedra de toque do modernismo pátrio. A segunda é o trabalho de Ricupero (Cf. 2018) sobre a antropofagia, que, num sentido muito próximo da embocadura do livro de Duarte, enxerga este movimento na chave de um projeto ideológico a partir do qual as supostas faltas brasileiras seriam tornadas

\footnotetext{
* Universidade de São Paulo - Faculdade de Filosofia, Letras e Ciências Humanas, R. do Lago, 717 - Butantã, São Paulo - SP, CEP 05508-080. rafael.marino50@gmail.com

iD https://orcid.org/0000-0002-2659-6434
} 
vantagens civilizacionais. O terceiro elemento é a crítica que Chibber (2013) faz ao pensamento pós-colonial, o qual poderia conduzir a uma celebração da particularidade sociocultural de um país perante o universal (Chibber, 2013, p. 288). A quarta diz respeito ao arcabouço teórico e metodológico sedimentado pelo campo do pensamento político e social brasileiro (Cf. Botelho e Schwarcz, 2011; Brandão, 2005; Bastos, 2007), o qual possui fronteiras poucos definidas frente a outras searas de pesquisa e nutre-se de variadas possibilidades pesquisa e de intercâmbio intelectual. Isso se daria porque tal campo de estudos entende que a vida política e social depende não somente de meios materiais, mas sim de recursos imateriais, à maneira, principalmente, das ideias (Cf. Botelho e Schwarcz, 2011). Deste modo, consoante ao pensamento de Brandão (Cf. 2005;2007;2010) e Bastos (Cf. 2002;2011), a força das ideias e seu peso histórico aparece a nós como inescapável à compreensão da dinâmica política, social e cultural de uma sociedade.

Dando consecução ao nosso argumento, exporemos alguns lineamentos dos pensamentos de alguns personagens destacados da tropicália sobre o Brasil. Para tal, lançaremos mão de alguns escritos e depoimentos de seus partícipes. Sabemos que há uma certa tensão em utilizarmos preferencialmente este tipo de material para análise de artistas e seu pensamento ao invés de nos dedicarmos mais detidamente ao que está em suas obras e formas, todavia acreditamos que a argumentação mais geral de Paula Braga (Cf. 2013; 2017), Frederico Coelho (Cf. 2010; 2017) e Schwarz (Cf. 2012) sobre a coerência e justeza na relação entre os escritos de Hélio Oiticica e Caetano Veloso, respectivamente, e suas produções podem ser estendidas aos outros tropicalistas, dado que todos tinham, em maior ou menor grau, forte intencionalidade e autoconsciência nos movimentações e deslocamentos que produziam ${ }^{1}$.

\section{EXERCÍCIOS DE LEITURA}

Caetano Veloso, em palestra proferida no ano de 1993 no Museu de Arte Moderna do Rio de Janeiro, intitulada "Diferentemente dos americanos do norte", anuncia certa mudança de posição em meio ao tropicalismo. Passando da atitude crítica e pessimista da tropicália a uma positivação em forma de profecia à maneira do sebastianismo, movimento atraiu sua atenção em vários escritos de sua lavra. Mudança que faz com que os elementos

\footnotetext{
${ }^{1}$ É interessante ter em vista aqui também os trabalhos de Duarte (cf. 2014) e Ricupero (cf. 2018), nos quais os autores utilizam, preferencialmente, os manifestos e artigos de revistas modernistas e antropófagos para escandir o projeto político ideológico de tais movimentos.
} 
que eram vistos como aspectos atrasados da cultura e da sociedade nacionais transformamse em vantagens relacionadas aos esforços de construção de uma nova civilização:

E aqui é o momento de tentar fazer o que fiz questão de frisar como sendo perigoso naquele arrazoado de Borges a respeito do modo de ser argentino: considerar vantajosas até mesmo as condições adversas com que a História nos presenteou; fazer, por exemplo, do fato de não termos sido eficientes o suficiente no extermínio dos índios como os nossos irmãos do Norte [...] e mesmo do fato de vermos que ainda estamos efetuando, com atraso, esse extermínio, uma oportunidade de nos tornarmos índios ao passo que nos reconhecemos ultra-ocidentais. E aqui quero citar um daqueles filósofos franceses cujas manias caricaturei mais cedo, mas que parece ser mesmo um grande sujeito. É Giles Deleuze que, naquele hilariante livro candidamente chamado $O$ que é filosofia? numa inacreditavelmente convincente jogada retórica, diz do filósofo que ele "deve tornar-se índio para o que o índio não sofra a miséria de ser índio". Mas só ganha o direito de arriscar tais inversões quem se sabe engajado num sonho grande e luminoso. Só na perspectiva do país artista superior que nós temos o dever de perceber que a História nos sugere que sejamos é que podemos revalorar aspectos do nosso atraso como sinais de que casualmente escapamos de uma servidão maior no misterioso desvelar de nosso destino (Veloso, 2005, p. 59-60).

Neste mesmo ensaio, Veloso afirma que mesmo nas paródias mais ácidas de sambas de exaltação ao Brasil feitas pela tropicália havia também, por trás delas, a exaltação do país. Porém, diferenciando-se do que chama de nacionalismo defensivo dos nacionalistas participantes da Música Popular Brasileira à época, teria proposto um nacionalismo agressivo. Deste modo, Veloso lança luz sobre a possibilidade de uma nação genuinamente brasileira e particular frente a outras nações ser construída a partir das especificidades culturais e sociais brasileiras, almejando uma espécie de modernidade alternativa ao país, mas que, ao fim e ao cabo, não conforma uma mudança efetiva das relações materiais e do lugar subalterno ocupado pelo Brasil em meio ao concerto das nações (Pires, 2017, p. 143) ${ }^{2}$. Algo similar também pode ser visto num manifesto, por vezes esquecido, dos tropicalistas pernambucanos", intitulado "O que é o nosso tropicalismo ou "vamos desmascarar o subdesenvolvimento", no qual dizem: “11. Não há nenhuma proposição estética. O que existe é uma atitude ética, uma política cultural. / 12. Por uma

\footnotetext{
2 É interessante observar, à vista de texto de Glaucia Villas Bôas (2011), que o tropicalismo poderia ser mais aproximado do programa modernista desenvolvido por artistas e intelectuais nos anos 1920 e 1930 no Brasil, voltados para a busca de uma brasilidade que deveria ser buscada na arte popular, indígena e negra. Deste modo, seguindo o argumento da socióloga, ele se afastaria do programa modernista construtivista, assentando na tentativa de construção de uma sociedade industrial moderna e universalista.

3 Por pernambucano, na verdade, nos referimos ao local de atuação direta destes intelectuais e artistas, mas não necessariamente sobre os seus estados de origem, visto que participavam dele pernambucanos, potiguares e paraibanos. Para mais sobre o tropicalismo pernambucano, ver Teles (Cf. 2012) e Aretakis (Cf. 2016).
} 
civilização nos trópicos, identificada nos mesmos problemas e em busca de suas próprias soluções” (apud Aretakis, 2016, p. 217).

Em sentido bastante aproximado, Hélio Oiticica ${ }^{4}$ irá transfigurar, na concepção de seus "Parangolés" e em sua obra "Tropicália", tanto as condições bastante precarizadas das construções populares e de favelas no Brasil (Cf. Davis, 2006; Maricato, 1996), quanto imagens estereotipadas do que seria um país tropical (araras, areias, plantas enormes) em princípio organizador estruturante em suas obras ${ }^{5}$. Dois movimentos que seriam responsáveis por caracterizar um estado da arte brasileira de vanguarda no mundo, confrontando-a com a arte $O p$ e arte $P o p$ - vanguardas tardias da década de 1960 e 1970. Nas palavras do próprio Oiticica:

Da ideia e conceituação de Nova Objetividade, criada por mim em 1966, nasceu a Tropicália, que foi concluída em princípios de 67 e exposta (projeto ambiental) em abril de 67. Com a teoria da Nova Objetividade queria eu instituir e caracterizar um estado da arte brasileira de vanguarda, confrontando-o com os grandes movimentos da arte mundial (Op e Pop) e objetivando um estado brasileiro da arte ou das manifestações a ela relacionadas [...]. A conceituação da Tropicália, apresentada por mim na mesma exposição, veio diretamente desta necessidade fundamental de caracterizar um estado brasileiro. Aliás, no início do texto sobre Nova Objetividade, invoco Oswald de Andrade e o sentido da antropofagia (antes de virar moda, o que aconteceu após a apresentação do Rei da Vela) como um elemento importante nesta tentativa de caracterização nacional. Tropicália é a primeiríssima tentativa consciente, objetiva, de impor uma imagem obviamente "brasileira" ao contexto atual da vanguarda e das manifestações em geral da arte nacional. Tudo começou com a formulação do Parangolé em 1964, com toda a minha experiencia com o samba, com a descoberta dos morros, da arquitetura orgânica das favelas cariocas (e consequentemente outras, como as palafitas do Amazonas) e principalmente das construções espontâneas, anônimas, nos grandes centros urbanos - a arte das ruas, das coisas inacabadas, dos terrenos baldios etc. [...] Com a Tropicália, porém, e que a meu ver se dá a completa objetivação da ideia. O Penetrável principal que compõe o projeto ambiental foi a minha máxima experiencia com as imagens, uma espécie de campo experimental com as imagens. Para isto criei como que um cenário tropical com plantas, araras, areia, pedrinhas (numa entrevista com Mario Barata no Jornal do Comercio a 21 de maio de 67, descrevo uma vivência que considero importante: parecia-me ao caminhar pelo recinto, pelo cenário da Tropicália, estar dobrando pelas "quebradas" do morro, orgânicas tal como a arquitetura fantástica das favelas; outra vivencia: a de "estar pisando a terra" outra vez). Por isso creio que a Tropicália, que encerra toda essa série de proposições, veio contribuir fortemente para essa objetivação de uma imagem brasileira total, para a derrubada do mito universalista da cultura brasileira, toda calcada na Europa e na América do Norte, num arianismo inadmissível aqui: na verdade, quis eu com a

\footnotetext{
${ }_{4}$ Para as aventuras e desventuras da recepção da obra de Oiticica ver Naves (2007).

5 Braga (Cf. 2017), contrariamente, argumentará que essa aproximação com a favela se constitui num processo de desintelectualização essencial à Nova Objetiva, a qual seria responsável por uma Nova Subjetividade, pautada numa metafísica política rebelde e coletiva, próxima de Deleuze, Negri e Rancière.
} 
Tropicália criar o mito da miscigenação - somos negros, índios, brancos, tudo ao mesmo tempo - nossa cultura nada tem a ver com a europeia, apesar de estar até hoje a ela submetida: só o negro e o índio não capitularam a ela. Quem não tiver consciência disto que caia fora. Para a criação de uma verdadeira cultura brasileira, característica e forte, expressiva ao menos, essa herança maldita europeia e americana terá de ser absorvida, antropofagicamente, pela negra e índia da nossa terra, que na verdade são as (micas significativas, pois a maioria dos produtos da arte brasileira e hibrida, intelectualizada ao extremo, vazia de um significado próprio (Oiticica, 1986, p. 66-68).

Uma posição artística que conforma uma ideia bastante particular de Brasil, baseada na especificidade das relações étnicas, sociais e dos aspectos culturais aqui conformados. As quais aparecem na obra e nos escritos de Oiticica como vantagens artísticas presentes nas formas de suas obras e que também são transfiguradas em características essenciais de uma vanguarda brasileira que poderia fazer frente ao pretenso universalismo do modernismo artístico europeu e seus desdobramentos mais tardios, como nas obras de Bridget Riley ( $P p$ art) e de Andy Warhol (Pop art).

É interessante, antes de passar ao pensamento de Zé Celso, que façamos alguns apontamentos sobre a ideia de miscigenação presente na citação anterior. Em primeiro lugar, é importante notar que há uma aproximação e um distanciamento frente ao pensamento de Gilberto Freyre. Aproxima-se, visto que, ao falar em miscigenação, apostase numa lógica de configuração nacional específica do Brasil desde a conformação de um povo dotado de originalidade racial frente ao outros povos e nação. Distancia-se, pois, diversamente de Freyre, a ênfase recai, como queria Penna (2017), na substituição antropofágica do vazio cultural branco, originário da cópia dos países europeus, pelos elementos e sujeitos indígenas e negro. Ou, como dizia Décio Pignatari (VELOSO; Gil., 2012, p. 129), os trópicos, em Gilberto Freyre, seriam vistos a partir da Casa Grande; nos tropicalistas, por seu turno, a visão seria desde a senzala. De todo modo, mesmo com essa distinção, seria o caso de se perguntar, segundo Abdias do Nascimento (2016): a continuidade da ideia de miscigenação não seria, mesmo que com diferenças e nuances, uma forma de genocídio dos povos negro e indígenas?

Noutro momento, será José Celso Martinez Corrêa que irá chamar a atenção para as especificidades do Brasil as quais deveriam ser figuradas numa forma de fazer teatro entendida como instrumento da realidade terceiro-mundista. Com isso, Corrêa formula uma crítica ao antigo Teatro Brasileiro de Comédia (TBC), por demais colonizado e mero veículo de badalação pequeno-burguesa. Nesse teatro do terceiro mundo, o indivíduo não deveria ser apenas conscientizado, mas preparado para uma ação imediata contra a situação 
de subdesenvolvimento de seus países. Nesse quadro, o Brasil é visto como portador das condições para se ter um teatro funcional e mais:

É um momento em que o povo brasileiro sente a necessidade do teatro porque sente necessidade de refletir e sentir o problema da ação. Não é portanto, uma fase de teatro bem comportado, mas de um teatro violento, bárbaro, criador, como tudo que está vindo à tona neste país. É um teatro que se comunica pela porra a uma plateia mistificada que aí está para receber mesmo vilões e outros bichos e objetos pela cara. $\mathrm{O}$ teatro moderno deve se radicalizar, no sentido de voltar à sua raiz, isto é, ao comportamento humano como nas sociedades primitivas. O papel a desempenhar no terceiro mundo é fatal. Jean-Paul Sartre diz que lamenta não ter nascido em um país de terceiro mundo. Régis Debray veio lutar em nossas barbas; o maior antropólogo do mundo Claude Lévis-Strauss, constrói toda a sua ciência a partir do exame dos trópicos. [...] O nosso mundo, o terceiro, não será construído por si, com a força de suas máquinas. Seu artifício é o homem, que terá primeiro que lutar contra os envolvimentos que lhe impedem o movimento, construindo assim o mundo de acôrdo com suas utopias, suas Maracangalhas, suas Pasárgadas, seus Eldorados. O Eldorado do terceiro mundo começa já na descoberta que um clima de ação e luta vale mais do que um ambiente burocrata e consumidor dos lixos alheios. Com isso o teatro redescobre sua função mais antiga, quase sagrada, de ser aquela arte destinada a dar mais força e confiança à arte do homem (Corrêa apud Bononi, 2012, p. 126-127).

Mesmo que impressione essa diferente ênfase de Corrêa quanto ao terceiromundismo, é preciso notar em seu escrito um elogio ao "primitivo" e ao "local" perante ao que é considerado colonialista e ao centro do capitalismo, algo que muito se aproxima ao orientalismo às avessas visto por Chibber (Cf. 2013) - e a exaltação do particular frente ao universal presente no pensamento pós-colonial ${ }^{6}$. Fazendo sistema com esta interpretação, é sugestivo lembrar que Schwarz (Cf. 2008) já havia indicado também que esta aposta na hipotética existência de uma estética do terceiro-mundo trazia em si um encobrimento dos conflitos de classe. Levando a uma noção ingênua, apesar de violenta, dos antagonismos internacionais e a uma visão romantizada do atraso, principalmente para aqueles que dele não sofrem as consequências, como é o caso dos supracitados Jean-Paul Sartre e Régis Debray, os quais, de um modo ou de outro, exaltavam as particularidades do chamado terceiro-mundo como positivas na luta de esquerda e em direção ao socialismo.

O mesmo comentário poderia ser estendido, com algumas nuances, a alguns textos de Glauber Rocha nos quais o cineasta baiano não só defende uma radicalização do sentido terceiro-mundista do cinema (Cf. Rocha, 2004), mas chega mesmo a propor que o cinema

\footnotetext{
${ }^{6}$ Por pós-colonial entendemos, aqui, como uma série de estudos e críticas, surgidas entre as décadas de 1960 e 1970, os quais, em linhas gerais, procuravam desfazer e desconstruir o eurocentrismo e as formas de interpretação dominantes forjados pela dominação territorial e subjetiva europeia em relação aos diversos povos ao redor do mundo. Para mais, ver as perspectivas, divergentes de Chibber (2013) e Prakash (1994).
} 
- não só brasileiro, mas em geral - deva ser feito desde um ponto de vista ideogramático. Para Rocha, o melhor ideograma que poderia servir como símbolo mais necessário ao seu projeto é o mito, a partir do qual as expressões culturais e artísticas iriam se referir e desde o qual seria construído o surrealismo dos povos latino-americanos, a saber: o tropicalismo. Ainda seguindo a exposição do cineasta baiano, esse surrealismo mítico especificamente brasileiro e latino-americano propiciaria a libertação do domínio da razão, que ainda agrilhoava o cinema de Jean-Luc Godard, por exemplo (Rocha, 2004, p. 150-154). É interessante notar que a argumentação de Rocha constrói uma contraposição entre o irracionalismo do mito terceiro-mundista e o racionalismo presente no cinema do primeiro mundo, de modo que aquele seria o elemento essencial para organizar os elementos específicos da cultura brasileira e latino-americana e transformá-los em forma fílmica.

Mesmo que, até agora, tenhamos exposto uma espécie de linhagem de pensamento sobre o Brasil e suas especificidades que aproxima a todos estes autores e suas produções em certa exaltação das especificidades nacionais como saídas artísticas, políticas e civilizacionais para o mundo, é necessário ter em vista a existência de discordância entre eles e que aqui serão, ao menos em parte, expostas.

A bem da verdade, até para podermos ser justos com o material de pesquisa, Basualdo (Cf. 2007) já havia apontado - sem tirar, necessariamente, maiores e mais sistemáticas consequências disto - uma discordância importante entre Hélio Oiticica e a dupla Caetano Veloso e Gilberto Gil, a qual liga-se à postura deles quanto à relação entre artes e o que podemos chamar de Indústria Cultural. Os dois últimos acreditavam haver um potencial democratizante e até mesmo disruptivo na integração da música à indústria cultural, dado que ela poderia tanto se desprovincianizar ao receber os influxos externos da música pop internacional, quanto poderia atingir o maior número de pessoas e efetivamente atingir as massas. Algo que fica bastante marcado nessas duas passagens:

Domingo [no parque] já devia estar pronto quanto Gil, que tinha deixado a Gessy Lever e se mudara com mulher e filhas para o Rio, recebeu um convite de não sei quem em Pernambuco para fazer uma temporada de apresentações no Recife. [...] O fato é que chegou no Rio querendo mudar tudo, repensar tudo - e, sem descanso, exigia de nós uma adesão irrecusável a um programa de ação que esboçava com ansiedade e impaciência. [...] Ele dizia que nós não podíamos seguir na defensiva, nem ignorar o caráter de indústria do negócio em que nos tínhamos metido. Não podíamos ignorar suas características da cultura de massas cujo mecanismo só poderíamos entender se o penetrássemos. Dizia-se apaixonado por uma gravação dos Beatles chamada "Strawberry Fields Forever", que, a seu ver, sugeria o que devíamos estar fazendo e pareciase com a "Pipoca moderna" da Banda de Pífanos. [...] Nada disso era 
propriamente novo para mim, excerto que tudo viesse assim de uma vez e tão sistematizado (Veloso, 2017, p. 152-153).

E nós estamos aqui para vender. Não fomos nós que fizemos da nossa música mercadoria. Mas ela só penetra quando vendida. Quem apronta essa onda toda em torno do nome tropicalismo é a imprensa (Gil apud Gil; Veloso, 2012, p. 130).

Já José Celso Martinez Corrêa, Hélio Oiticica e até mesmo Glauber Rocha tinham suas restrições frente à indústria cultural, a estética por ela exaltada e seus desdobramentos comportamentais e de pensamento. Poder-se-ia argumentar que isso, em boa medida, devese aos campos artísticos distintos nos quais as obras destes artistas se concentravam e ao fato de os contornos da indústria fonográfica, frente aos mercados de artes plásticas e cênicas, serem dotados de maior musculatura, o que tornaria seus procedimentos e modismos inescapáveis. Porém, é necessário notar que o cinema já havia se desenvolvido enormemente e o aparato por trás dele já possuía contornos de grandes conglomerados globais (Cf. Cook, 1990) - dos quais decorriam consequências e formulações estéticas cada vez mais pasteurizadas -, como poderia ser visto no cenário musical, e nem por isso Glauber Rocha deixou de tecer duras críticas ao cinema mainstream, pelo contrário. De todo modo, exporemos, mesmo que sumariamente, algumas das posições dos artistas acima citados sobre o ponto levantado com o intuito de clarificar a nossa argumentação.

Corrêa, já nos inícios da tropicália, incomodava-se com tal epíteto e argumentava que isto não poderia nem ser considerado um movimento unificado. Para o dramaturgo, a tropicália deveria ser vista, na verdade, como uma série de rupturas estéticas e políticas desenvolvidas no mesmo período por vários campos das artes e que ganhou essa nomenclatura por meio dos setores midiáticos e o que considera setores pequenoburgueses que buscavam tornam essas transgressões numa marca vendável, numa brincadeira ou em um folclore neocolonial (Corrêa, 1998, p. 126-127) ${ }^{7}$. Nesse diapasão, um companheiro de palco de Corrêa, a saber, Renato Borghi (Cf. 2017) comenta que em dezembro de 1968, com a temporada da peça O rei da vela, no Rio de Janeiro, o grupo Oficina e a tropicália passaram por um processo de forte consagração mercantil. Era comum a presença dos artistas tropicalistas em festas da alta sociedade carioca e modelitos alcunhados tropicalistas passaram a ser vendidos a preços inimagináveis, de modo que, nas palavras de Borghi: "Nós atacávamos o sistema, mas o sistema, sem que percebêssemos, começava a nos devorar pelos pés" (Borghi, 2017, p. 90). No entanto, o ator e dramaturgo ressalta que apesar desta ofensiva mercantil, a antropofagia que lhes era característica

\footnotetext{
${ }^{7}$ Para mais sobre o Teatro Oficina em meio ao tropicalismo, ver Patriota (Cf. 2003).
} 
permanecia com a sua força crítica e continuava "devorando o imenso cadáver gangrenado do Brasil por dentro. Autópsia canibal" (Ibid.).

Hélio Oiticica demonstrava incômodo análogo ao de Corrêa e ao de Borghi. Conforme argumenta o artista visual, a sua obra, Tropicália, bem como o tropicalismo, teriam por objetivo deglutir de maneira radicalmente antropofágica a arte europeia e dos Estados Unidos da América a partir de um referencial negro e índio, os únicos realmente significativos em nossa cultura colonizada ou híbrida. Mas o que se vê, muitas vezes, é a seguinte atitude:

\begin{abstract}
Burgueses, subintelectuais, cretinos de toda espécie, a pregar tropicalismo, tropicália (virou moda) - enfim, a transformar em consumo algo que não sabem direito o que é. Ao menos uma coisa é certa: os que faziam stars and stripes já estão fazendo suas araras, suas bananeiras etc., ou estão interessados em favelas, escolas de samba, marginais anti-her6is (Cara de Cavalo virou moda) etc. Muito bom mas não se esqueçam que há elementos aí que não poderão ser consumidos por esta voracidade burguesa: o elemento vivencial direto, que vai além do problema da imagem, pois quem fala em tropicalismo apanha diretamente a imagem para o consumo, ultra superficial, mas a vivência existencial escapa, pois não a possuem - sua cultura ainda é universalista, desesperadamente a procura de um folclore, ou a maioria das vezes nem isso (Oiticica, 1986, p.108-109).
\end{abstract}

Em Glauber Rocha, por seu turno, são conhecidas as críticas feitas ao cinema tradicional feito no centro do capitalismo e as suas reverberações na América-latina e no chamado terceiro mundo (Cf. Rocha, 2004). Contra isto, Rocha irá propor uma estética da fome, profundamente violenta e que apresenta a fome e a miséria não como folclores específicos da periferia capitalista, mas como componentes essenciais da acumulação capitalista mundial, os quais são obliterados pela estética hollywoodiana ou pelo que chama de cinema digestivo - burgueses, alegres, puramente industriais e sem mensagem (Ibid., p. 65). Radicalizando essa postura, o cineasta baiano dirá que o tropicalismo deveria propiciar relações ainda mais libertas em seus filmes, os quais, ao menos em parte deles, emulavam, em alguns aspectos, relações burguesas fechadas e não antropofágicas. E mais, esse verdadeiro surrealismo latino-americano, como chama a tropicália, deveria, por meio da figuração ideogramática e alegórica de mitos nacionais (Cf. Xavier, 2012), calar fundo no inconsciente popular, fazendo frente aos filmes mais comerciais e americanos.

É necessário levarmos em consideração aqui o fato de o arcabouço analítico e de método proveniente do campo do pensamento político e social brasileiro ter nos permitido olhar com maior vagar e atenção para os escritos, ideias e lances argumentativos dos artistas aqui analisados. Tal procedimentação, cobrindo searas distintas da tropicália, ainda não se fazia presente na discussão sobre a tropicália e suas manifestações, as quais ou se 
direcionam apenas para sua produção musical ou para artísticas específicos e seus ensaios, como é o caso das obras, por exemplo, de Schwarz (Cf. 2012), Braga (Cf. 2013;2017) e Coelho (Cf. 2010;2017). Destarte, o pensamento político e social brasileiro permitiria um novo olhar renovado sobre o tropicalismo.

\section{CONSIDERAÇÕES FINAIS}

Propusemos, ao longo de nossa exposição, uma perspectiva de leitura e interpretação que poderia dar uma nova visada aos estudos do tropicalismo, qual seja: o estudo da tropicália desde o campo do pensamento político e social brasileiro. Nesse sentido, apostamos que as ciências sociais podem fornecer novas visadas sobre as artes e os movimentos artístico, ao mesmo tempo em que o campo das artes e de seus estudos podem fornecer objetos, perspectivas e até mesmo diagnósticos críticos essenciais para as áreas que compõe as ciências sociais e suas pesquisas.

De forma mais pormenorizada, é possível vislumbrar, desde estas notas, que o tropicalismo, além de um movimento artístico e cultural, pode ser entendido também como ponta de lança essencial para constituição de uma forma específica de ver o Brasil no mundo, em que o que era considerado atrasado ou arcaico no país é entendido, a partir desta forma de pensar, como uma potencialidade ou uma via brasileira para o mundo e seus problemas. Isso ainda demanda maiores estudos e desenvolvimento, não obstante os esquemas mentais e ideias estão aqui lançados.

Voltando mais especificamente ao nosso exercício de leitura, seguindo exemplos como os de Braga (Cf. 2013; 2017), Coelho (Cf. 2010;2017), Duarte (Cf. 2014; 2018) e Ricupero (Cf. 2014), procuramos apontar a necessidade de olharmos com maior vagar para os escritos e depoimentos dos artistas tropicalistas, e não só para suas produções, para melhor entendermos e aquilatarmos o pensamento político e social que galvanizava a todos e que fora essencial para suas obras e atuações políticas e estéticas e, portanto, o tropicalismo em si. Com isso, deixe-se claro, não pretendíamos propor um abandono da análise das formas artísticas e culturais, mas, tão somente, mostrar a potencialidade existente em pesquisarmos o tropicalismo com um ponto de vista imantado pelo pensamento político e social brasileira, seus procedimentos e ensaios.

Recebido para publicação em 12/05/2020.

Aceito em 01/08/2020. 


\section{REFERÊNCIAS}

ALAMBERT, F. A realidade tropical. Revista IEB, v.1, n. 54, p. 139-150, mar. 2012.

ANDRADE, Oswald de. A utopia antropofágica. São Paulo: Globo, 2011.

ARETAKIS, F. P. O tropicalismo pernambucano: histórias de um "tigre de vanguarda". 2016. 220p. Dissertação (Mestrado em História) - Programa de pós-graduação em História da Universidade Federal de Pernambuco.

BASUALDO, Carlos. Vanguarda, cultura popular e indústria cultural. In: (org.). Tropicália: uma revolução na cultura brasileira. São Paulo: Cosac Naify, 2007, p. 11-31.

BASTOS, É. R. Atualidade do pensamento social brasileiro. Sociedade e Estado, v. 26, n. 2, p. 51-70, ago. 2011.

BASTOS, Élide Rugai Pensamento social da escola sociológica paulista. In: MICELI, S. (Org.). O que ler na ciência social brasileira: 1970-2002. São Paulo: Sumaré; Brasília: ANPOCS, 2002, p. 183-230.

BONONI, J. G. José Celso Martinez Corrêa: entre efeitos de sentidos e condições de produção. Revista espaço acadêmico, v.1, n. 134, p. 124-135, mai. 2012.

BORGHI, Renato. Posfácio. In: ANDRADE, O. de. O rei da vela. São Paulo: Companhia das Letras, 2017, p. 82-91.

BOTELHO, A.; SCHWARCZ, L. Pensamento social brasileiro, um campo vasto e ganhando forma. Lua Nova, v.1, n. 82, p. 11-16, jan./mar. 2011.

BRAGA, P. Hélio Oiticica: singularidade, multiplicidade. São Paulo: Perspectiva, 2013.

BRAGA, P. Nova objetividade e nova subjetividade: Hélio Oiticica rumo ao coletivo". MODOS, v.1, n. 3, p. 123-135, set. 2017

BRANDÃO, Gildo Marçal. Ideias e argumentos para o Estudo da História das Ideias Políticas no Brasil. In: MARTINS, C. B. e LESSA, R. (orgs). Horizonte das Ciências Sociais no Brasil. São Paulo, Editoras Discurso Editorial e Barcarolla, 2010, p.367-376.

BRANDÃO, G. M. Linhagens do Pensamento Político Brasileiro. Dados - Revista de Ciências Sociais, v. 48, n. 2, p.231-269, jan./mar. 2005.

BRANDÃO, G. M. Linhagens do Pensamento Político Brasileiro. São Paulo: Editora HUCITEC, 2007.

CAMPOS, A. de. Balanço da bossa e outras bossas. São Paulo: Editora Perspectiva, 1974.

CHIBBER, V. Post-colonial theory and the spectre of capital. London: Verso, 2013.

COELHO, C. A tropicália: cultura e políticas nos anos 60. Tempo social, v. 1, n. 2, p. 159-176, jul./dez. 1989. 
COELHO, F. Livro ou livro-me: os escritos babilônicos de Hélio Oiticica. Rio de Janeiro: Eduerj, 2010.

COELHO, F. 1970: pause/play. ARS, v. 15, n. 30, p. 133-148, mai./ ago. 2017.

COOK, D. A history of narrative film. Nova York/ London: Norton \& Co., 1990.

CORRÊA, Z. C. M. Primeiro ato: cadernos, depoimentos, entrevistas (1958-1974). São Paulo: Editora 34, 1998.

COUTINHO, C. N. Cultura e sociedade no Brasil: ensaios sobre ideias e formas. São Paulo: Editora Expressão Popular, 2011.

DAVIS, M. Planeta favela. São Paulo: Boitempo, 2006.

DUARTE, P. Palavra modernista: vanguarda e manifesto. Rio de Janeiro: Casa da Palavra, 2014.

DUARTE, P. Tropicália ou panis et circencis. São Paulo: Editora Cobogó, 2018.

GIL, Gilberto e VELOSO, Caetano. Debate na FAU. In: COHN, S.; COELHO, F. (Orgs.). Tropicália. Rio de Janeiro: Azougue Editorial, 2012. p. 126-133.

MARICATO, Hermínia. Metrópole na periferia do capitalismo. São Paulo: Hucitec, 1996.

NASCIMENTO, Abdias do. O Genocídio do negro brasileiro: processo de um racismo mascarado. São Paulo: Perspectiva; Ipeafro, 2016.

NAVES, Rodrigo. Um azar histórico: sobre a recepção das obras de Hélio Oiticica e Lygia Clark. In: NAVES, R. O evento e o moinho: ensaios sobre arte moderna e contemporânea. São Paulo: Companhias das Letras, 2007. p. 192-223.

PATRIOTA, R. A cena tropicalista no Teatro Oficina de São Paulo. História, v. 22, n. 1, p. 135-163, jan./ jul. 2003.

PRAKASH, G. Subaltern studies as postcolonial criticism. The American Historical Review, v. 99, n.5, p. 1475-1490, dez. 1994.

RICUPERO, B. O "original" e a "cópia" na antropofagia. Revista Sociologia \& Antropologia, v. 08, n. 3, p. 875-912, set.-dez., 2018.

ROCHA, G. Revolução do cinema novo. São Paulo: Cosac Naify, 2004.

SCHWARZ, R. Martinha versus Lucrécia. São Paulo: Companhia das Letras, 2012.

SCHWARZ, R. O pai de família e outros estudos. São Paulo: Companhia das Letras, 2008.

TELES, J. Do frevo ao manguebeat. São Paulo: Editora 34, 2012. 
VILLAS BÔAS, Glaucia. Arte e política: a lógica das interpretações. Revista Sociedade e Estado, v. 26, n. 3, p. 487-499, set.-dez., 2011.

XAVIER, I. As alegorias do subdesenvolvimento: cinema novo, tropicalismo e cinema marginal. São Paulo: Cosac Naify, 2012. 


\title{
TROPICALISM AND ITS IDEOLOGICAL POLITICAL PROJECT: A READING EXERCISE
}

\begin{abstract}
This essay intends to expose some research notes about tropicalism. It is known that tropicália has already been the subject of several studies in the human and social sciences, however it is betting on another angle for its study: its political and ideological project. This project, according to our hypothesis, would have succeeded in consolidating a way of thinking about Brazil that, roughly speaking, was based on the transfiguration of Brazil's social and cultural specificities into qualities and responses of our Brazilian 'civilization' to the world and its problems. Continuing our argument, we will expose some lines of thoughts about Brazil of some outstanding characters from tropicália. To this end, we will make use of some writings and testimonies from its participants.
\end{abstract}

Keywords: Brazilian political and social thought; aesthetics and politics; tropicalism.

\section{EL TROPICALISMO Y SU PROYECTO POLÍTICO IDEOLÓGICO: UN EJERCICIO DE LECTURA}

Resumen: Este ensayo pretende exponer algunas notas de investigación sobre el tropicalismo. Se sabe que tropicália ya ha sido objeto de varios estudios en las ciencias humanas y sociales, sin embargo, está apostando por otro ángulo para su estudio: su proyecto político e ideológico. Este proyecto, según nuestra hipótesis, habría logrado consolidar una forma de pensar sobre Brasil que, a grandes rasgos, se basó en la transfiguración de las especificidades sociales y culturales de Brasil en cualidades y respuestas de la 'civilización' brasileña a los problemas mundiales. Continuando con nuestro argumento, expondremos algunas líneas de pensamiento de algunos personajes destacados de la tropicália sobre Brasil. Para ello, haremos uso de algunos escritos y testimonios de sus participantes.

Palabras claves: Pensamiento político y social brasileño; estética y política; tropicalismo.

Rafael Marino - Doutorando e Mestre (2018) em Ciência Política pela FFLCH - USP, graduado em Ciências Sociais pela mesma instituição. É editor da revista Leviathan - cadernos de pesquisa política e técnico de programação cultural no SESC-SP. É autor do livro Formação e forma no pensamento brasileiro, Editora Appris. 